\title{
Book Review of Boissière M. et al. Biodiversity and Local Perceptions on the Edge of a Conservation Area, Khe Tran Village, Vietnam. Indonesia: CIFOR, 2006. Version 1.
}

\author{
Minh-Hoang Nguyen \\ Ritsumeikan Asia Pacific University, Beppu, Oita Prefecture, Japan \\ Email: ng19m6tk@apu.ac.jp
}

Recently, the Vietnam government has increasingly shifted the forest management from centralization to the approach that is more favorable of local communities and organizations. However, little is known about the recognition of local people's rights, knowledge, and perspectives, so it creates challenges on informing stakeholders the views of people living nearby the forest and dependent on the natural resources from the forest. For strengthening the local capacity to plan and implement locally relevant forest management, there have been many projects being implemented. One of those is the Stakeholder and biodiversity at the local level project, which is a three-year collaboration among Center for International Forestry Research (CIFOR), the Swiss Development Cooperation (SDC), and the Tropenbos International-Vietnam (TBI-V). The project aims to explore the needs and preferences of local people in areas with high autonomy in decision making about forest management, especially poor communities. The book written by Boissière et al. (2006) records the project design, methodology, and findings of the project.

The book is structured into ten chapters. The first five chapters describe the project backgrounds, methodologies, and study sites, while the next four chapters are to present findings of the research. The last chapter summarizes all the results and offers recommendations for conservation management and other land use planning that involve the local population. Even though the research was conducted in one area, the authors provide convincing reasons why the study site was selected. The project is undertaken in Khe Tran village, which covers an area of around 200 ha and is located to North-West of Hue city. The village is located in the buffer zone of Phong Dien Nature Reserve (PDNR) and chosen because of three reasons.

First, Vietnam is an ethnicity rich country in which 53 ethnic minorities are living along with Kinh (the majority ethnic group in Vietnam), so studying the local community knowledge of the mixing group between minority and majority ethnicities would provide more significant insights into the local perceptions. Second, after the discovery of Edward's Pheasant in the mountains of Phong Dien district, a new nature reserve will be introduced in the village's vicinity, which might create a huge potential for local communities' involvement. Lastly, although many projects have been implemented to investigate mines and infrastructure, few are conducted for gaining experiences in land use planning.

The methodology employed in the project is the Multidisciplinary Landscape Assessment (MLA). This method is relatively complex and requires the incorporation of multiple methods rooted from different disciplines of social sciences (anthropology, ethnobotany, socioeconomics) and natural sciences (botany, ecology, geography, pedology). The complexity of this method also reflects through the research aspects of project members: ethnobotany, socio-economy, ecology, and botany. Thanks to the MLA approach, the statistics provided by the book cover many aspects of the area, like the land types, resources, ethnobotanical knowledge, and local perceptions on biodiversity. Such data could be reused for future socio-environmental assessment and further studies in the region. 
Potential readers of this book could be interdisciplinary researchers, doctoral candidates that want to study the local population's perceptions on biodiversity and natural resources, and other project operators. The structure of the book is designed similarly, in my opinion, a doctoral dissertation, which renders information systematically and comprehensively. For anyone interested in the citizens' perceptions towards biodiversity in a developing country, the book's Chapter 9 - "Local perspectives on conservation," provides helpful directions to focus. In particular, in Chapter 9, the perceptions of villagers are classified into four categories: definition of conservation, life with conservation, life without conservation, and role to play in the future management of Phong Dien National Reserve Area. Besides the classification, the authors also compare perception differences in those aspects between the lower part and upper part villagers.

Besides the land type and botanical knowledge, the project content is primarily about the villagers' perceptions towards biodiversity. Still, the content regarding the cultural aspects seems to be neglected in the book, or more particularly the research design and findings. Although the authors mention that information regarding biodiversity and forest was gathered from cultural sources (e.g. history of the village, social organization, stories and myths, and religion, etc.), the culture related information presented in the book is still insufficient given the highly diverse ethnographical and cultural characteristics in the area. Vuong (2020b) suggests that environmental degradation can be halted and ecological conditions can be restored by adopting an environmental-healing culture. Considering this perspective, I think the inclusion of cultural aspects in environmental studies/projects concerning human is vital.

Furthermore, the cultural perception towards the environment of local communities can also be navigated, examined, and amended using the mindsponge theory (Vuong and Napier 2015, Vuong 2016). The theory assumes that anyone has a set of core values (a.k.a. mindset), and the mindset is protected by the buffer zone from any external cultural changes/shocks. Based on this theory, populations' mindset regarding the environment can be changed from exploitation to symbiosis, and eventually to restoration perceptions.

In conclusion, the book provides valuable insights into the local communities' perceptions towards biodiversity and forest management by showing the design and findings of a real project implemented in a particular area. These insights might be beneficial for researchers, doctoral candidates, and readers who are interested in citizens' perceptions towards biodiversity in a developing country. Nevertheless, despite focusing on the local perceptions, cultural aspects seem to be mistreated, which lessened the value of the book substantially. Moreover, the limitations of the project also seem to be missing in the book, which lessens the transparency (Vuong 2020a).

\section{References}

Boissière, Manuel, Imam Basuki, Piia Koponen, Meilinda Wan, and Douglas Sheil. 2006. Biodiversity and local perceptions on the edge of a conservation area, Khe Tran village, Vietnam: CIFOR.

Vuong, Quan-Hoang. 2020a. "Reform retractions to make them more transparent." Nature 582:149. doi: doi: 10.1038/d41586-020-01694-x.

Vuong, Quan Hoang. 2016. "Global mindset as the integration of emerging socio-cultural values through mindsponge processes: A transition economy perspective." In Global Mindsets, edited by John Kuada, 123-140. Routledge. 
Vuong, Quan Hoang. 2020b. The semiconducting principle of monetary and environmental values exchange. OSF Preprints.

Vuong, Quan Hoang, and Nancy K Napier. 2015. "Acculturation and global mindsponge: an emerging market perspective." International Journal of Intercultural Relations 49:354-367. 